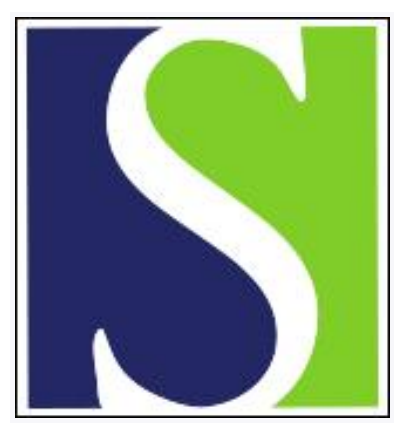

Scand J Work Environ Health 1985;11(4):307-310

https://doi.org/10.5271/sjweh.2218

Issue date: Aug 1985

Determination of dimethylethylamine in air samples from iron foundries by isotachophoresis.

by Hansen L, Sollenberg J, Uggla C

This article in PubMed: www.ncbi.nlm.nih.gov/pubmed/4059893

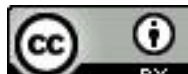




\title{
Determination of dimethylethylamine in air samples from iron foundries by isotachophoresis
}

\author{
by Lars Hansén, MSc, Jan Sollenberg, PhD, Charlotta Uggla ${ }^{1}$
}

\begin{abstract}
HANSÉN L, SOLLENBERG J, UGGLA C. Determination of dimethylethylamine in air samples from iron foundries by isotachophoresis. Scand J Work Environ Health 11 (1985) 307-310. A method for the determination of dimethylethylamine in workroom air has been developed. Static gas standards of the amine in air were used to evaluate different sampling techniques. The analysis was performed by isotachophoresis. The sampling equipment of choice was midget impinger flasks of glass or polystyrene containing $10 \mathrm{ml}$ of hydrochloric acid $(50 \mathrm{mmol} / \mathrm{l})$. The method was used in a field study of three different iron foundries where air samples were taken. The dimethylethylamine concentration found was in the range $0.5-155 \mathrm{mg} / \mathrm{m}^{3}$. No pretreatment of the samples was necessary, and no interfering substances from the air in the foundries affected the analysis.
\end{abstract}

Key terms: cold-box, gas standard, mold core, polyurethane catalyst.

In the production of mold cores in the foundry industry the cold-box technique is of increasing importance. The mold cores are made of fine granular sand, 4,4'-diphenylmethane diisocyanate (MDI), and a liquid phenolic resin. The reaction is catalyzed by a gaseous tertiary amine which is pressed through the mixture. Triethylamine (TEA) has thus far been the dominating amine catalyst. But for the last few years the use of the more volatile dimethylethylamine (DMEA) seems to be increasing in Sweden.

DMEA is a liquid with a strong ammoniacal odor. It has a boiling point of $35^{\circ} \mathrm{C}$ and is very flammable with a flashpoint of $-36^{\circ} \mathrm{C}(8)$. In animal experiments it has been indicated that DMEA is very irritating to the eyes, remarkably irritating to the mucous membrane in the respiratory organ, and slightly irritant to the skin (8). The hygienic standard for DMEA in workroom air is $75 \mathrm{mg} / \mathrm{m}^{3}$ in Denmark, whereas no corresponding value has been adopted in Sweden.

Gas chromatography is generally used for the analysis of DMEA. Two such methods using aromatic polymers or ethylene glycols as stationary phases have been described by Lindsay Smith and co-workers $(6,7)$ for the analysis of DMEA and some other aliphatic amines. Casselman \& Bannard (1) have indicated the problems connected with the gas chromatographic analysis of amines. Recently Dalene et al (2) published a method for the analysis of TEA and other aliphatic amines by gas chromatography. Volpi (10) has described a colorimetric and a gas chromatographic method for DMEA in workroom air. Schütz \& Wolf (9) have used a gas chromatographic

\footnotetext{
1 National Board of Occupational Safety and Health, Research Department, Solna, Sweden.
}

Reprint requests to: Mr L Hansén, National Board of Occupational Safety and Health, Research Department, S-171 84 Solna, Sweden. method to measure DMEA and several other compounds in exhaust gases from different processes in foundries, among them cold-box core-making.

In connection with an extensive study on the occupational environment in foundries and as part of our investigations on analytical methods for amines used in industry $(3,4,5)$, we have developed an alternative method for the analysis of DMEA in air samples by isotachophoresis (ITP). The method has been used in a field study of three different foundries and is presented in this report.

\section{Materials and methods}

\section{Preparation of gaseous standards}

Static gaseous standards of DMEA in air were made in home-made sacks, as shown in figure 1. A sheet of aluminum laminated with a $12-\mu \mathrm{m}$ thick polyester layer (Åkerlund \& Rausing, Lund, Sweden) was folded to form a sack $(125 \times 80 \mathrm{~cm})$ with the polyester layer inside. The edges were affixed with tape adhesive on both sides. The inlet system for the diluting air was a polytetrafluoroethylene (PTFE) tube (inner diameter $4 \mathrm{~mm}$ ) fastened with PTFE nuts directly on the wall of the sack. Purified diluting air (charcoal filter) was introduced into the sack, and the volume (generally $100 \mathrm{l}$ ) was registered on a gas meter. DMEA was injected directly through the laminate by a microliter syringe. In this step the DMEA and the syringe had to be chilled to avoid losses due to evaporation. A gentle tapping of the sack was used to mix the gas. Concentrations between 15 and $75 \mathrm{mg} / \mathrm{m}^{3}$ were generated.

\section{Air sampling}

Laboratory experiments. Samples were taken from the sack by different techniques. Sampling in $10 \mathrm{ml}$ 


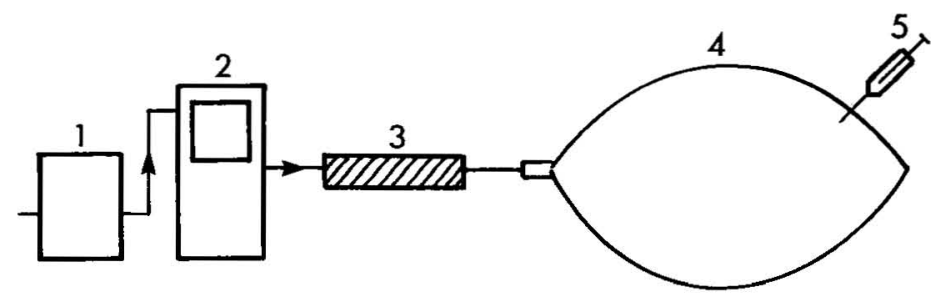

Figure 1. A static system for the production of gaseous standards of dimethylethylamine in air. $(1=$ pump, $2=$ gas meter, $3=$ charcoal tube, 4 = aluminum-laminated polyester sack, $5=$ microliter syringe)

of hydrochloric acid $(\mathrm{HCl})(50 \mathrm{mmol} / \mathrm{l})$ was compared by bubbling the gaseous amine standard through home-made midget impinger flasks of polystyrene, spill-proof midget impinger flasks of glass (Svenska labglas $\mathrm{AB}$, Stockholm, Sweden), and gas washing bottles of glass. Sampling was also performed on silica gel tubes $[6 \mathrm{~mm}$ outer diameter $\times 70 \mathrm{~mm}$, no 226-10, SKC Inc, Eighty Four, Pennsylvania, United States (USA)]. When comparisons were made with glass flasks or silica gel tubes, they were run in parallel with the polystyrene flasks. Portable sampler pumps (Anatole J Sipin Co, New York, New York, USA) were used at a flow rate of $200 \mathrm{ml} / \mathrm{min}$. During the sampling the flow rate was intermittently checked with a soap film meter connected to the outlet of the pump.

For desorption of the amine from the silica gel the following solvents were used: water, $\mathrm{HCl}(50 \mathrm{mmol} / \mathrm{l})$, and $\mathrm{HCl}(100 \mathrm{mmol} / \mathrm{l})$ : ethanol $(1: 1)$. Each gel section was transferred to separate glass vials, $1.0 \mathrm{ml}$ of the desorption solvent was added to the vial with the sorbent layer, and $0.5 \mathrm{ml}$ of the the same solvent was added to the back-up sorbent layer vial. The vials were then shaken for $30 \mathrm{~min}$ in a laboratory shaker.

Foundry study. Air samples were taken in three different iron foundries. Foundry A had several small and rather old machines in the area where small mold cores $(<1 \mathrm{~kg})$ were produced. Five persons were exposed. Foundry B had two modern machines which were fully enclosed. Mold cores of small and medium sizes $(1-4 \mathrm{~kg})$ were produced, and four persons were exposed. Foundry $\mathrm{C}$ had one modern large machine (enclosed), and one old machine in which large and medium-sized mold cores $(5-15 \mathrm{~kg})$ were produced. Three persons were exposed. In all three foundries the core machines were ventilated, and in foundries $B$ and $\mathrm{C}$ the exhaust gases were burned in a butane flame.

Both personal and stationary samples were collected. The stationary samples were taken about $1.5 \mathrm{~m}$ above the floor level close to the machines and in the area where newly made cores were stored. At all sampling sites polystyrene flasks were used. When the samples were collected in glass flasks or on silica gel tubes, they were run in parallel with the polystyrene flasks. The sampling occurred on $2 \mathrm{~d}$ when the production was said to be normal.

\section{Concentration of the samples}

The sensitivity of the analysis can be increased by concentration of the absorption solution from the impinger flasks. The procedure involves transferring $5 \mathrm{ml}$ of the solution to a polypropylene tube, which was put in a thermostated heating block, and evaporating the solution to dryness at $80^{\circ} \mathrm{C}$. The process was speeded up by passing a gentle stream of nitrogen over the surface of the solution. To avoid losses, probably due to sublimation of the hydrochloride of the amine, the process was stopped when dryness was reached in the tubes. The evaporation rate for the absorption solution was $1 \mathrm{ml} / \mathrm{h}$. The residue was dissolved in $500 \mu \mathrm{l}$ of distilled water. An aliquot of the solution was injected directly into the isotachophoretic instrument for analysis.

\section{Analysis}

The analysis was performed by isotachophoresis with an LKB 2127 Tachophor (LKB-Produkter AB, Bromma, Sweden) equipped with a conductivity detector and a capillary tube (PTFE, inner diameter $0.5 \mathrm{~mm}$, length $230 \mathrm{~mm}$ ). The capillary was thermostated at $15^{\circ} \mathrm{C}$. The leading electrolyte was potassium hydroxide $(10 \mathrm{mmol} / \mathrm{l})$ in $0.4 \%$ (weight/volume) hydroxypropylmethylcellulose (90 HG 15 Pas, Dow Chemicals, Midland, Michigan, USA). The $\mathrm{pH}$ of the solution was adjusted to 8.8 by the addition of L-Valine (solid) (Sigma, St Louis, Missouri, USA). The terminating electrolyte was tris(hydroxymethyl)aminomethane $(20 \mathrm{mmol} / \mathrm{l})$ in $\mathrm{HCl}(5 \mathrm{mmol} / \mathrm{l})$, $\mathrm{pH}$ 8.5. The sample volume was between 2 and $10 \mu \mathrm{l}$, the migration current was $100 \mu \mathrm{A}$, and the time of analysis was about $12 \mathrm{~min}$. DMEA was quantified from measurements of the zone lengths on the graph through a pocket lens, magnifying 10 times, with a graduated scale.

\section{Results and discussion}

\section{Laboratory experiments}

An analytical separation of DMEA and TEA is shown in figure 2. A calibration graph for DMEA analyzed by isotachophoresis was made from standard solutions of DMEA in water. It was linear in the range tested ( 1 to $150 \mathrm{nmol}$ ). The practical detection 
limit for DMEA in this system was about $1 \mathrm{nmol}$. (This value corresponds to $7.3 \mu \mathrm{mol}$ of amine in a sample concentrated 10 times, which can be obtained from 41 of air containing a DMEA content of $2 \mathrm{mg} / \mathrm{m}^{3}$.)

The results of the laboratory experiments of sampling DMEA from a sack with two different impinger flasks are shown in table 1. By "overall recovery" we mean the quotient of the DMEA concentration determined by the isotachophoretic analysis to the calculated value of the concentration in the sack. The uncertainty of the determinations includes errors from the preparation of the gas standard, sampling, concentration of the absorption solution, and the final analysis. The recoveries were similar for the two types of impinger flasks.

If necessary the absorption solution can be concentrated 10 to 20 times with negligible loss of DMEA.

In one experiment gas washing bottles of glass with sintered glass filters were used for sampling about $400 \mu \mathrm{g}$ of DMEA from gas standards. The recoveries had a slightly greater variation in comparison to those obtained when impinger flasks were used (recovery $=96 \%, \mathrm{SD}=13, \mathrm{~N}=5$ ).

The experiments with adsorption tubes gave unsatisfying recoveries with the desorption solutions used. However, the use of solid sorbents for the sampling of amines will be dealt with in another work.

\section{Foundry study}

The results of the determinations of DMEA in three different foundries are shown in table 2 . The figures indicate that the personal samples are slightly higher than the stationary ones taken in the vicinity of the machine. However the samples taken under the cover show very high concentrations of DMEA. Consequently the worker who takes the mold cores out of the machine will have a higher exposure than the stationary samples indicate.

All samples in the field study were taken at random, and the investigation is not to be regarded as an occupational examination of the exposure to DMEA in

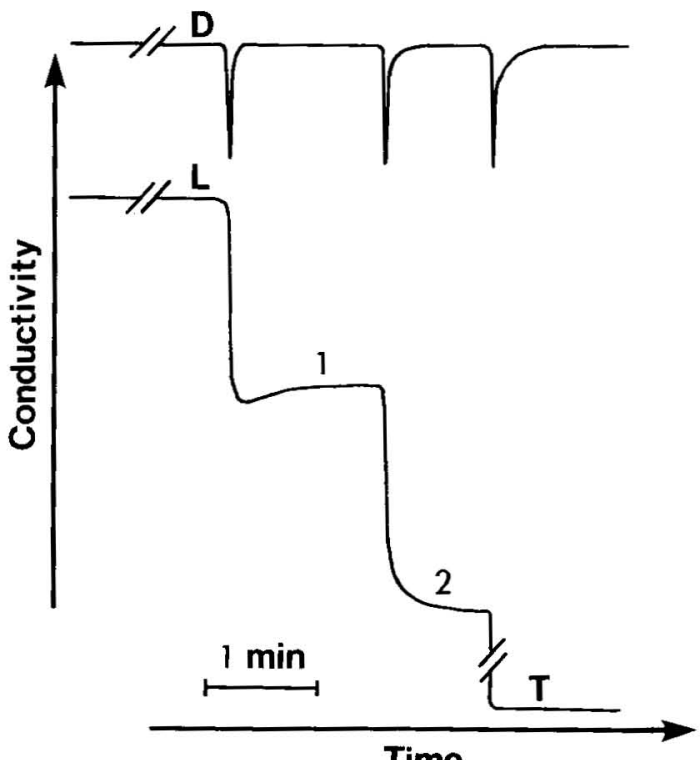

Figure 2. Isotachophoretic separation of dimethylethylamine $(23 \mathrm{nmol}, 1)$ and triethylamine $(20 \mathrm{nmol}, 2)$. The migration current was $50 \mu \mathrm{A}$, and the scale indicates $1 \mathrm{~min}$ of recording. $(L=$ leading electrolyte, $T=$ terminating electrolyte, $D=$ differential signal)

Table 1. Analysis of dimethylethylamine (DMEA) from static gas standards in an aluminum-laminated polyester sack. Comparison between sampling in midget impinger flasks of polystyrene and glass at three different concentration levels.

\begin{tabular}{|c|c|c|c|c|c|c|c|c|c|c|c|c|c|}
\hline \multirow{4}{*}{$\begin{array}{l}\text { DMEA } \\
\text { generated } \\
\left(\mathrm{mg} / \mathrm{m}^{3}\right)\end{array}$} & \multirow{4}{*}{$\begin{array}{l}\text { DMEA } \\
\text { sampled } \\
(\mu \mathrm{g})\end{array}$} & \multicolumn{12}{|c|}{ Overall recovery $(\%)$} \\
\hline & & \multicolumn{6}{|c|}{ Polystyrene } & \multicolumn{6}{|c|}{ Glass } \\
\hline & & \multicolumn{3}{|c|}{ Unconcentrated } & \multicolumn{3}{|c|}{ Concentrated 10 times } & \multicolumn{3}{|c|}{ Unconcentrated } & \multicolumn{3}{|c|}{ Concentrated 10 times } \\
\hline & & $\begin{array}{c}\text { Number } \\
\text { of } \\
\text { samples }\end{array}$ & Mean & SD & $\begin{array}{c}\text { Number } \\
\text { of } \\
\text { samples }\end{array}$ & Mean & SD & $\begin{array}{c}\text { Number } \\
\text { of } \\
\text { samples }\end{array}$ & Mean & SD & $\begin{array}{c}\text { Number } \\
\text { of } \\
\text { samples }\end{array}$ & Mean & SD \\
\hline $\begin{array}{l}14 \\
35-47 \\
63-70\end{array}$ & $\begin{array}{c}200 \\
250-350 \\
340-420\end{array}$ & $\begin{array}{r}4 \\
15 \\
12\end{array}$ & $\begin{array}{l}103 \\
104 \\
104\end{array}$ & $\begin{array}{r}6 \\
9 \\
10\end{array}$ & $\begin{array}{l}4 \\
7 \\
-\end{array}$ & $\begin{array}{l}90 \\
97 \\
.\end{array}$ & $\begin{array}{r}17 \\
4 \\
.\end{array}$ & $\begin{array}{r}7 \\
12 \\
6\end{array}$ & $\begin{array}{r}100 \\
99 \\
97\end{array}$ & $\begin{array}{l}6 \\
4 \\
7\end{array}$ & $\begin{array}{l}7 \\
9 \\
-\end{array}$ & $\begin{array}{c}101 \\
97 \\
.\end{array}$ & $\begin{array}{l}5 \\
6 \\
.\end{array}$ \\
\hline
\end{tabular}

Table 2. Analysis of dimethylethylamine (DMEA) during cold-box core-making in three different iron foundries.

\begin{tabular}{|c|c|c|c|c|c|c|}
\hline \multirow[b]{2}{*}{ Type of sampling } & \multicolumn{2}{|c|}{ Foundry A } & \multicolumn{2}{|c|}{ Foundry B } & \multicolumn{2}{|c|}{ Foundry C } \\
\hline & $\begin{array}{l}\text { Number of } \\
\text { samples }\end{array}$ & $\begin{array}{c}\text { DMEA } \\
\left(\mathrm{mg} / \mathrm{m}^{3}\right)\end{array}$ & $\begin{array}{l}\text { Number of } \\
\text { samples }\end{array}$ & $\begin{array}{c}\text { DMEA } \\
\left(\mathrm{mg} / \mathrm{m}^{3}\right)\end{array}$ & $\begin{array}{l}\text { Number of } \\
\text { samples }\end{array}$ & $\begin{array}{c}\text { DMEA } \\
\left(\mathrm{mg} / \mathrm{m}^{3}\right)\end{array}$ \\
\hline $\begin{array}{l}\text { Personal } \\
\text { Stationary (at the machine) } \\
\text { Stationary (under the cover) }\end{array}$ & $\begin{array}{l}5 \\
8 \\
1\end{array}$ & $\begin{array}{l}4.5-34 \\
0.7-14 \\
155\end{array}$ & $\begin{array}{l}4 \\
8 \\
-\end{array}$ & $\begin{array}{l}1.8-7.1 \\
0.5-3.5\end{array}$ & $\begin{array}{l}3 \\
9 \\
2\end{array}$ & $\begin{array}{l}7.4-15 \\
1.8-10 \\
77-95\end{array}$ \\
\hline Stationary (far from the machine) & - & . & 5 & $0.5-0.9$ & - & . \\
\hline
\end{tabular}


iron foundries but as a test of the sampling and analytical method.

The results of samples analyzed directly by isotactophoresis (x) were compared with those of the same samples that were concentrated up to 20 times (y). The equation of the regression line obtained was: $y=1.02 \mathrm{x}-1.11$, and $\mathrm{r}=0.997$ for 22 samples. The samples originated from two of the foundries, and most of them were from stationary sampling sites close to the machines. The concentration range of DMEA in air was 2 to $155 \mathrm{mg} / \mathrm{m}^{3}$. Schütz \& Wolf (9) report the range $19-185 \mathrm{mg} / \mathrm{m}^{3}$ for DMEA in foundries during cold-box core-making.

The present method can be used to determine DMEA in air at a concentration of $2 \mathrm{mg} / \mathrm{m}^{3}$ in iron foundries when sampling $4 \mathrm{l}$ of air. No pretreatment of the samples before analysis is necessary, and no interference affects the analysis.

The unique quality of the isotachophoretic analysis to discriminate interfering substances which are not charged at the prevailing $\mathrm{pH}$ of the system makes the evaluation of the separation rational and convenient.

\section{References}

1. Casselman AA, Bannard RAB. Gas chromatography of some polyamines on three porous polymer columns.
J Chromatogr 88 (1974) 33-40.

2. Dalene M, Mathiasson L, Jönsson JÅ. Trace analysis of free amines by gas-liquid chromatography. J Chromatogr 207 (1981) 37-46.

3. Hansén L, Kristiansson B, Sollenberg J. Determination of triethylamine and 2-dimethylaminoethanol by isotachophoresis in air samples from polyurethane foam production. In: Holloway CJ, ed. Analytical and preparative isotachophoresis. Walter de Gruyter \& Co, Berlin / New York 1984, pp 81-87.

4. Hansén L, Kristiansson B, Sollenberg J. A method for the determination of ethylenediamine in workroom air. Scand J Work Environ Health 10 (1984) 95-98.

5. Hansén L, Sollenberg J, Wiberg K. Determination of butylamine in air samples by isotachophoresis. J Chromatogr 312 (1984) 489-491.

6. Lindsay Smith JR, Roark J, Waddington DJ. Gas chromatographic analysis of aliphatic amines: The use of ethylene glycols as stationary phases. J Chromatogr 42 (2) (1969) 183-194.

7. Lindsay Smith JR, Waddington DJ. Gas chromatographic analysis of aliphatic amines using aromatic polymers. Anal Chem 40 (3) (1968) 522-527.

8. Morel C, Cavigneaux A, Protois JC. Diméthyléthylamine. Cah Notes Doc 86 (1977) 121-124.

9. Schütz A, Wolf D. Gase und Dämpfe an Giessereiarbeitsplätzen. Messung, Beurteilung, Schutzmassnahmen. Giesserei 67 (1980) 68-73.

10. Volpi E. Determinazione della dimetil etil ammina negli ambienti di lavoro. Inquinamento 19 (1977) $81-83$.

Received for publication: 4 February 1985 